\title{
An analytical expression for the $K$ shell ionization cross section of some heavy atomic elements by electron impact
}

\author{
Salim H. Al-Shamma Muzahim I. Azawi Lubna H. Ismail \\ Department of Physics / College of Education \\ University of Mosul
}

Received

22 / 06 / 2010
Accepted

10 / 07 / 2011

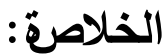

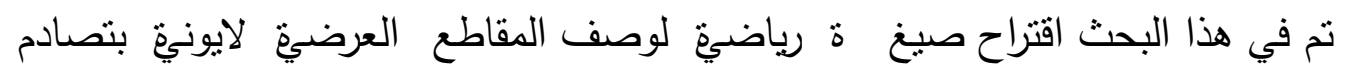

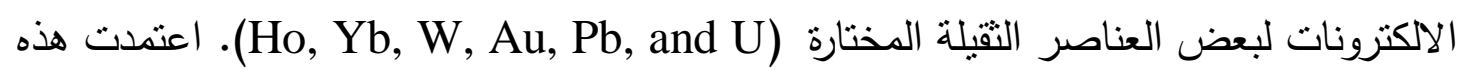

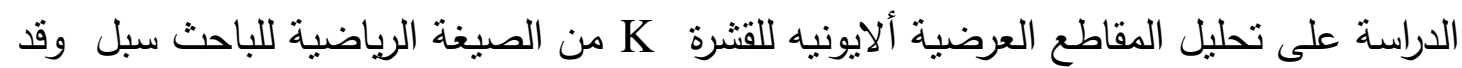

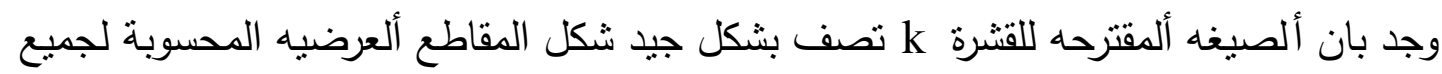
العناصر إضافة إلى اتفاق جيد مناسب مع قيم المقاطع العرضية المحسوبة .

\section{Abstract:}

An analytical expression is proposed to describe the $\mathrm{k}$ shell ionization cross section by electron impact for some heavy atomic elements $(\mathrm{Ho}, \mathrm{Yb}, \mathrm{W}, \mathrm{Au}, \mathrm{Pb}$, and $\mathrm{U})$ had been presented. This study is based on the analysis of the calculated cross section using Sbell formalism. The proposed analytical expression had been found to be fitted very well with the shape of the calculated data for all atomic elements with an acceptable agreement in the values of the calculated cross section.

\section{1- Introduction:}

The ionization of atom by electron impact is a process of great importance in atomic physics. The inner shell ionization cross section by electron impact finds applications in a number of fields for quantitative analysis for material characterization such as electron probe microanalysis, Auger electron spectroscopy, electron energy loss spectroscopy, radiation physics, astrophysics and environmental physics $[1,2]$. 
The cross section for the production of a vacancy in the atomic $\mathrm{k}$ shell which we call simply by a $\mathrm{K}$ shell $(\mathrm{l}=0)$ ionization cross section and whose value are pointed out by [2]. The cross section for the removal of atomic inner shell electron by electron impact had been investigated by means of both experimental and theoretical methods. Measurements of $\mathrm{K}$ shell ionization cross section electron impact in the energy range of (6.540) keV had been obtained [3-5].

A semi-phenomenological method to compute the cross section for bound shell ionization of atoms by a relativistic electron impact had been suggested by [6]. An empirical formula is proposed by [7] to describe the $\mathrm{k}$ shell ionization cross section for a wide range of atomic number and overvoltages. Deutsch-Mark formalization to calculate the $\mathrm{K}$ shell ionization cross section by electron impact for the atomic elements such as (Fe, Co, Mn, Ti, $\mathrm{Zn}$, No, and Mo) had been proposed by [8]. An empirical model suggested by [9] for calculation of $\mathrm{k}$ shell ionization cross section by electron impact for the (60) atomic elements from $\mathrm{H}$ to $\mathrm{U}$ ( $Z=1$ to $Z=92$ ) for the electron energy range from threshold to ultrarelativistic.

An analytical expression for $\mid \mathrm{K}$ and $\mathrm{L}$ shells cross sections of neutral atoms near ionization threshold by electron impact over a wide range of atomic numbers and overvoltages had been proposed by [10].

In this work, an analytical expression had been suggested to describe the $\mathrm{K}$ shell ionization cross section by electron impact to fit any data for the atomic elements ( $\mathrm{Ho}, \mathrm{Yb}, \mathrm{W}, \mathrm{Au}, \mathrm{Pb}$ and $\mathrm{U}$ ) over a wide range of the incident energies.

\section{2- Theoretical frame:}

In order to obtain an analytical expression for $\mathrm{K}$ shell ionization cross section for the elements ( $\mathrm{Ho}, \mathrm{Yb}, \mathrm{W}, \mathrm{Au}, \mathrm{Pb}$, and $\mathrm{U})$, a curve fitting tool had been used to plot that data obtained from the literature with high resolution figure. After plotting each figure of each element by using Sbell formalism [9], then the first and second derivatives of the data where calculated by Matlab with help of the code Runge-Kutta fourth order of the analytical. Then the first derivative data were then plotted, and the fitting parameters $\mathrm{A}, \mathrm{B}$ and $\mathrm{C}$ where found for the analytical expression as follows

$$
\begin{gathered}
\frac{d \sigma}{d E}=A E^{2} x \frac{\tanh (\sigma)}{\sigma}+B E+C \ldots \ldots . \\
\text { where } \sigma \text { is the cross section. }
\end{gathered}
$$

From the second derivative, the minima and maxima were found and also if there was any singularity in the plot.

The proposed analytical expression given in equation (1) was then solved numerically using Runge-Kutta $\left(4^{\text {th }}\right.$-order $)$ to study its fitness for each element. 
The present proposed expression, as it provides simple and direct calculation of $\sigma$. This expression is comparable to the another expression,e.g., [10] as

$$
\sigma(U)=\frac{A_{n}(Z)}{B_{n}(U)+U} \ln (U) \ldots \ldots . . .
$$

where $\mathrm{U}$ is the reduced energy and $\left(\mathrm{A}_{\mathrm{n}}\right.$ and $\mathrm{B}_{\mathrm{n})}$ are fitting parameters.

Also, the expression of the calculation of cross section had been given in an other formula [11]:

$$
\sigma=4.5 \times 10^{-14} \sum n \frac{\operatorname{lin}(E / I)}{E I}
$$

Where $\mathrm{n}$ is the number of electrons in the (nl) shell

$E$ is the incident energy

I is the ionization energy

\section{3 - Results and discussion:}

An analytical expression as mentioned in the theoretical frame is used to describe the $\mathrm{k}$ shell ionization cross section for the atomic elements (Ho ( $Z=67), Y b(Z=70), W(Z=74), A u(Z=79), P b(Z=82)$ and $\mathrm{U}(\mathrm{Z}=92))$ over a wide range of incident energies.

In this work, an analytical expression had been suggested to describe the $\mathrm{K}$ shell ionization cross section by electron impact to fit any data for the atomic elements $(\mathrm{Ho}, \mathrm{Yb}, \mathrm{W}, \mathrm{Au}, \mathrm{Pb}$ and $\mathrm{U})$ over a wide range of the incident energies.

The present data and calculated data by Sbell formalism (see Ref.[9]) were drawn in the left and right sides of figures (1-3) respectively for comparison.

Fig (1) shows the $\mathrm{K}$ shell ionization cross section for $\mathrm{Ho}$ and $\mathrm{Yb}$ atoms as a function of the incident energy. For Ho atom as shown in the top of fig.(1), one can notice from this figure that there is accepted between the present data and the calculated data for the $\mathrm{k}$ shell cross section in the range $\left(10^{3}-10^{5}\right) \mathrm{keV}$ incident electron energy the present data indicate a higher value in the cross section than the calculated cross section. For $\mathrm{Yb}$ atom it is shown in the bottom of figure.

Fig(2) shows the $\mathrm{K}$ shell ionization cross section as a function of incident energy for $\mathrm{Au}$ (top figure) and $\mathrm{W}$ (bottom figure) atoms. One can see from these figures that there are reliable and accepted agreement between the present and calculated data.

Fig (3) shows the K shell ionization cross section as a function of incident energy for $\mathrm{Pb}$ (top figure) and $\mathrm{U}$ (bottom figure) atoms. One can find these figures that there are satisfactory agreements between the present and calculated data

A further study had been done for the parameters (A), (B), and (C) in the analytical expression for the $\mathrm{K}$ shell cross section for each 
particular atomic number. The behavior of these parameters as a function of atomic numbers are presented in Fig.(4)..

One can conclude from this work that the analytical expression proposed here represent a convenient approach to $\mathrm{k}$ shell ionization cross section for the elements between $(67-92)$ and incident energy between $\left(300-10^{5}\right) \mathrm{keV}$ in a simple way.
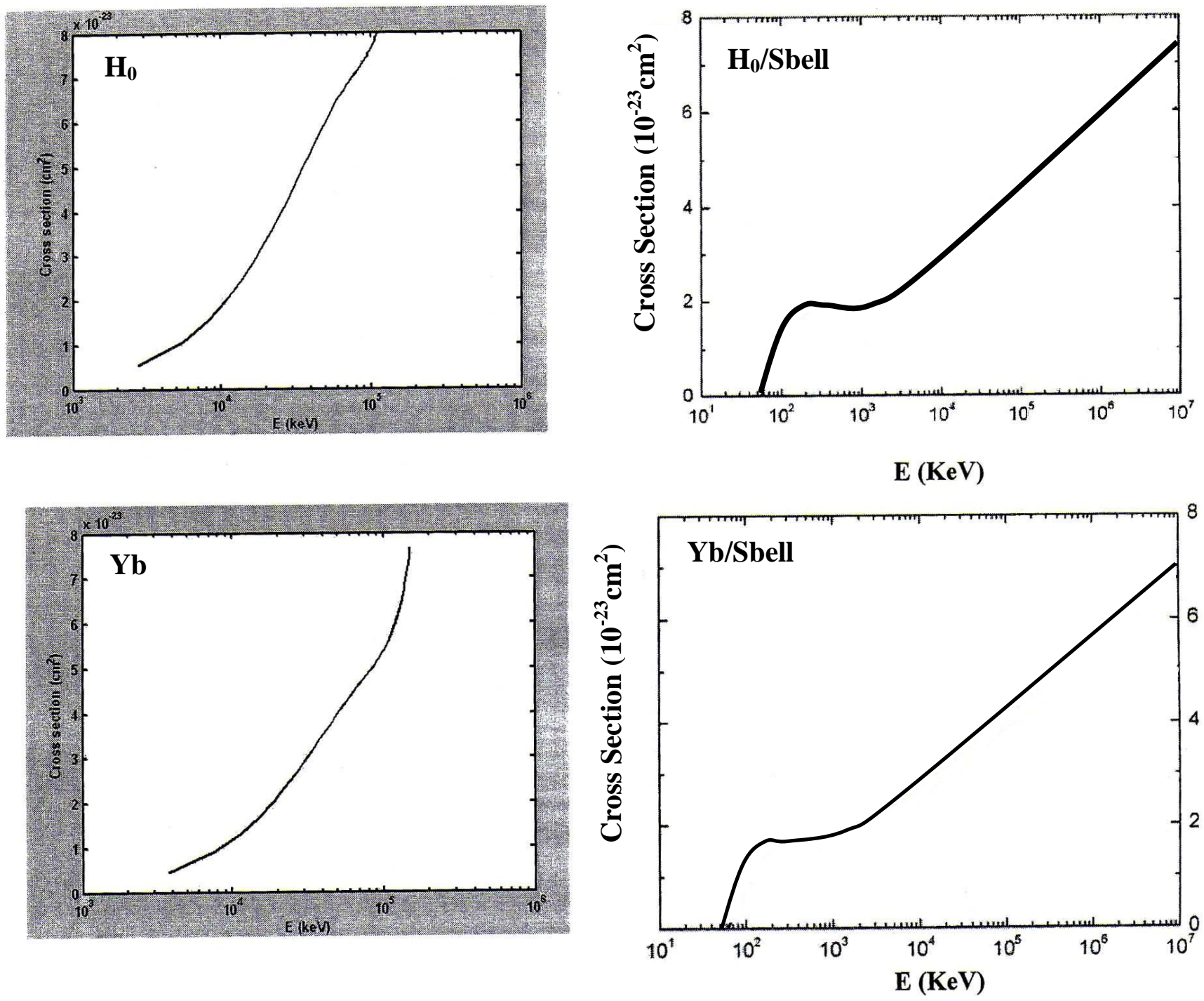

Fig (1) K shell ionization cross section as a function of incident energy for the atomic elements $\mathrm{Ho}$ and $\mathrm{Yb}$. The present and calculated data for $\mathrm{K}$ shell cross section are drawn in the left and right sides respectively. 

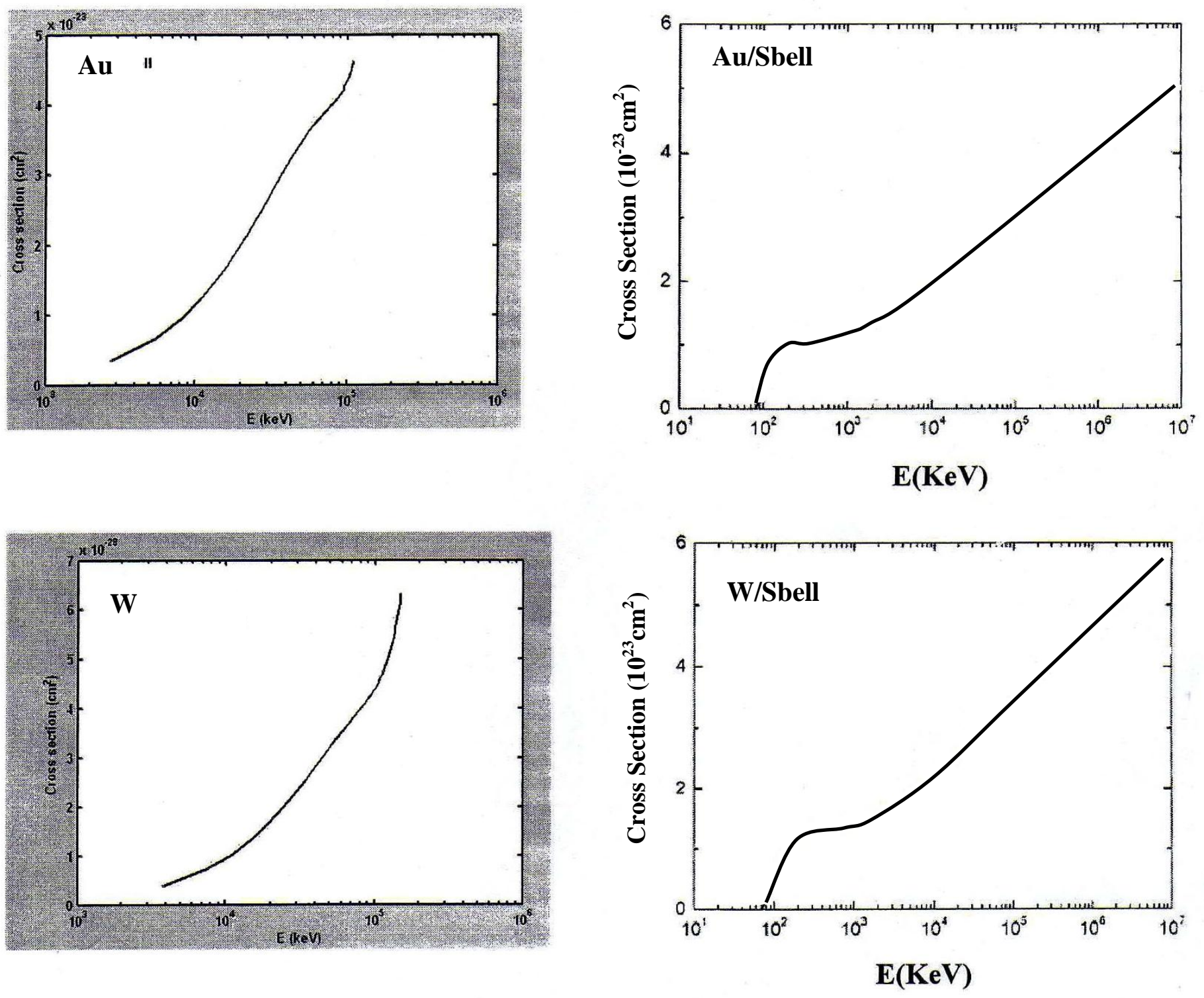

Fig (2): K shell ionization cross section as a function of incident energy for the atomic elements $\mathrm{Au}$ and $\mathrm{W}$. The present and calculated data for the $\mathrm{K}$ shell cross section are drawn in the left and right sides respectively. 

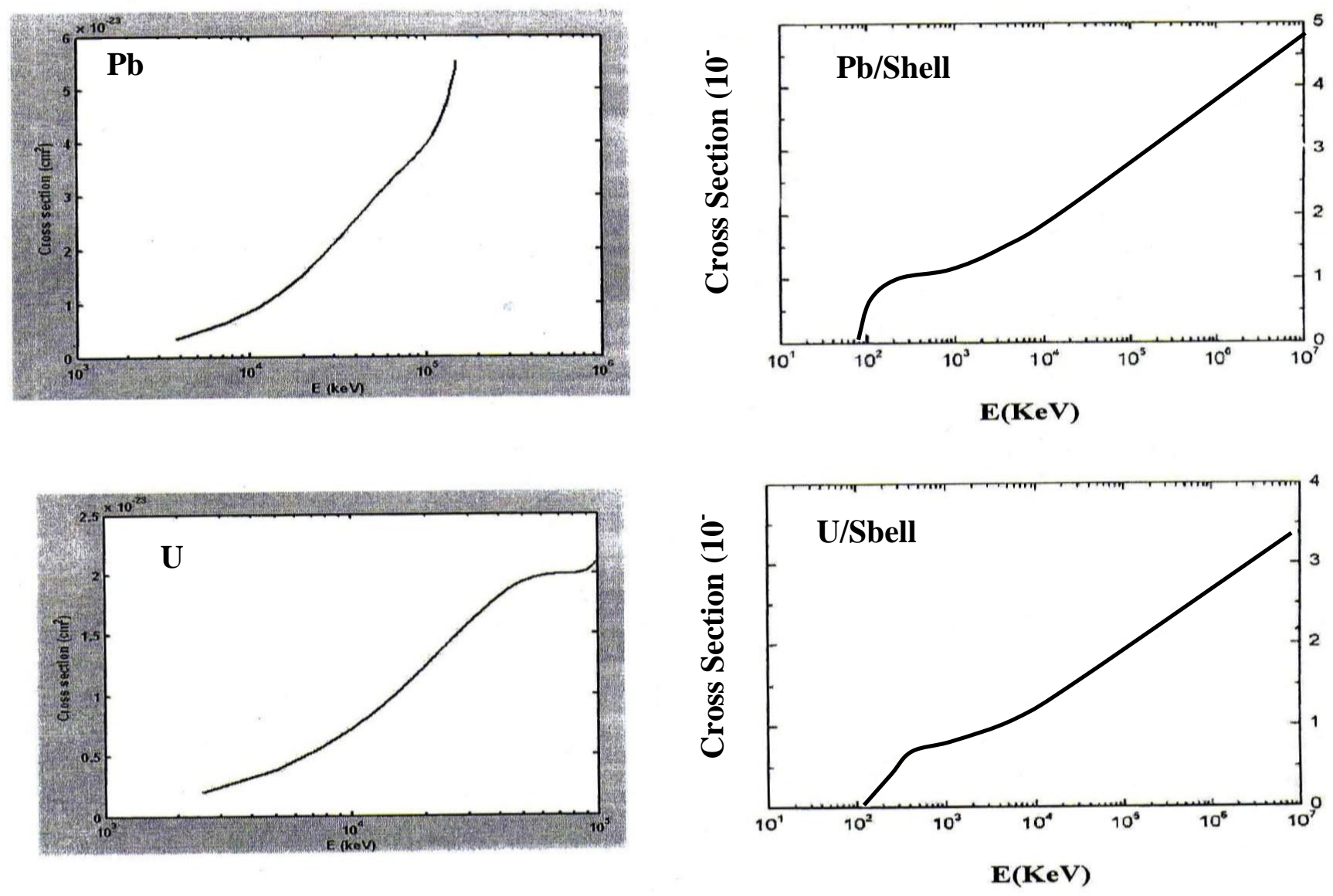

Fig (3): K shell ionization cross section as a function of incident energy for the atomic elements $\mathrm{Pb}$ and $\mathrm{U}$. The present and calculated data for $\mathrm{K}$ shell cross section are drawn in the left and right sides respectively. 
Salim H. Al-Shamma \& Muzahim I. Azawi \& Lubna H. Ismail
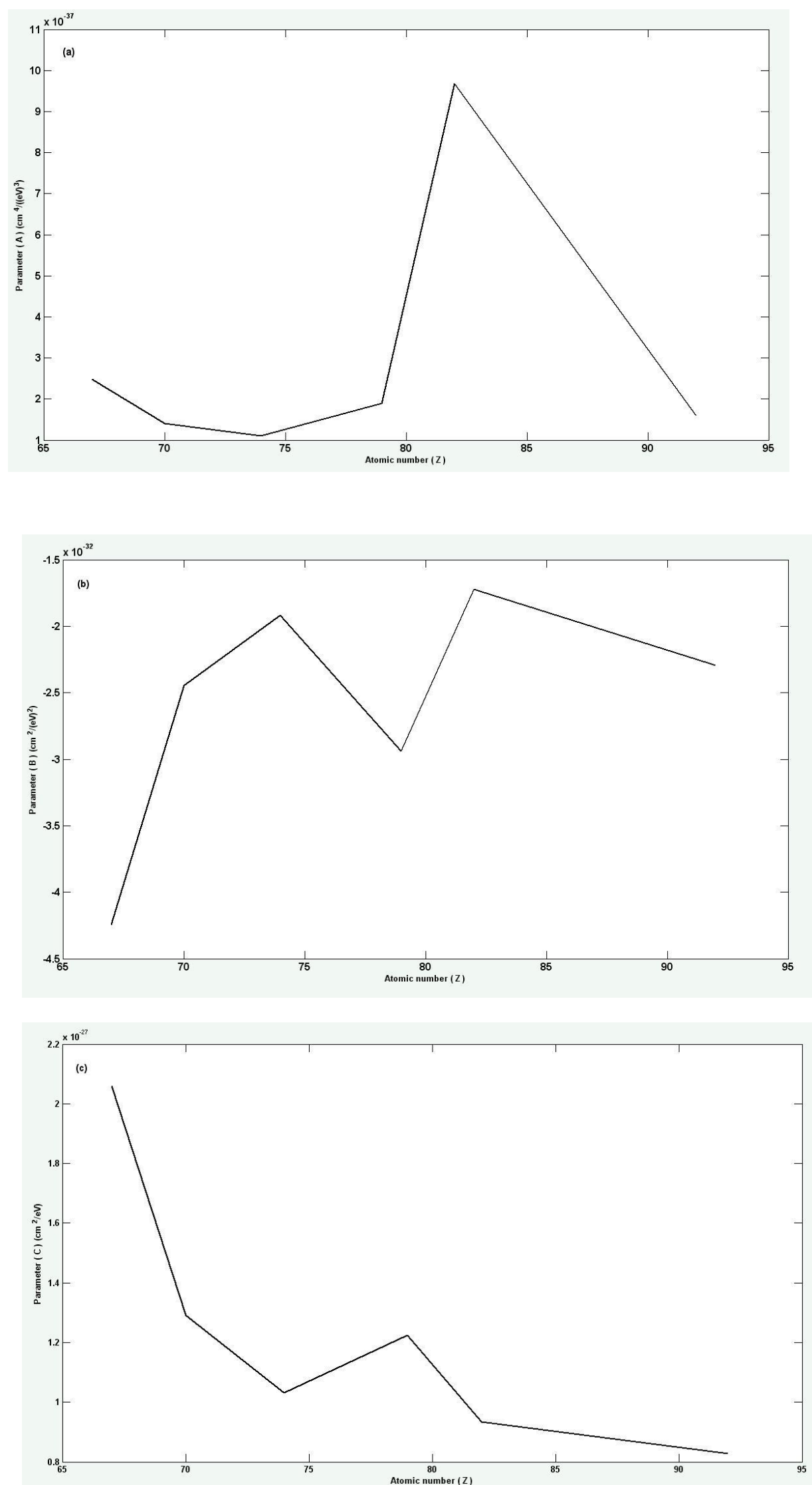

Fig.(4): The variations of the parameters $A, B \& C$ with atomic number of the atoms under study. 


\section{4 - Conclusions:}

The analytical expression suggested in this work represents a convenient and good approach to produce the $\mathrm{k}$ shell ionization cross section for the selected atomic elements ( $\mathrm{Ho}, \mathrm{Yb}, \mathrm{Au}, \mathrm{W}, \mathrm{Pb}$, and $\mathrm{U}$ ) over incident energy range between $\left(300-10^{5}\right) \mathrm{keV}$ in a straight way.

The analytical expression proposed represents the general shape of $\mathrm{k}$ shell cross section with reliable agreement with the calculated cross section using Sbell formula.

\section{References}

1) Power, C. J. (1976), Rev. Mod. Phys. 48. 33.

2) Power, C. J. (1985), Electron impact ionization, ed. T D Mark and G. H. Dunn (Wein; Springer).

3) Lioet, X, Merlet, C. and Salvat, F. (2000) J. Phys. B: At. Mol Phys. 33, $3761-3772$.

4) Merlet, C, Liovet, $X$ and Salvat, F. (2004), Phys. Rev. A67, o32708.

5) Baydas, E, Orhan, E and Buyukyildiz, M. (2009), Turk. J. Phys. 33, $311-316$.

6) Mayol, R. and Salvat, F. (1990), J. Phys. B: At. Mol. Opt. Phys.23 2117.

7) Tang, C.H, An, Z., Fan. X.Q., Luo, Z. M..(2001), Chin Phys. Letter. 48, 8, 1053.

8) Deutsch, H., Becker, K., Gstir, B. and Mark T.D (2002) International Journal of mass spectroscopy 213, $5-8$.

9) Talukder, M. R., Bose, M. R. and Takamur, S. (2008) Inter.J. mass spectroscopy, 269, 118.

10) Campos, C. S., Vasconcellos, M., Trincavelli, J. C. and Segui, S. (2007) J. Phys. B: At. Mol. Opt. Phys. 40, 3835 - 3841.

11) Bernshtam, V. A., Ralchenko, Y. and Maron. Y. (2000), J. Phys. B: Atomic, Molecular and Optical Phys. 33, 5025-5032. 